\title{
Adaptation to Climate Change by Australian Farmers
}

\author{
John Freebairn
}

Department of Economics, University of Melbourne, Melbourne, VIC 3010, Australia; j.freebairn@unimelb.edu.au

check for updates

Citation: Freebairn, J. Adaptation to Climate Change by Australian

Farmers. Climate 2021, 9, 141.

https://doi.org/10.3390/cli9090141

Academic Editor: Chris Swanston

Received: 11 August 2021

Accepted: 14 September 2021

Published: 16 September 2021

Publisher's Note: MDPI stays neutral with regard to jurisdictional claims in published maps and institutional affiliations.

Copyright: (C) 2021 by the author. Licensee MDPI, Basel, Switzerland. This article is an open access article distributed under the terms and conditions of the Creative Commons Attribution (CC BY) license (https:/ / creativecommons.org/licenses/by/ $4.0 /)$.
Abstract: Climate change in the form of higher temperatures, changes of rainfall patterns, and for some, more natural disasters will reduce the returns from current farming choices on what to produce and the production methods. Variation of climate change across regions and uncertainty about the magnitudes of change call for a diverse mix of adaptations to climate change across different regions and individual farms. This paper considers the institutional structure for effective climate change adaptation by Australian farms. It is argued that a rerun of the history of successful adaptation of farms to new technology, changes in output and input prices, natural climate variation, and other circumstances can be repeated for climate change adaptation. Individual farms can benefit from incentives and rewards to revise their decisions, which will combine with better individual outcomes. Complementary support by the government includes the provision of climate change and weather forecast information, support for research into new technology, help to evaluate the pros and cons of alternative choices, and provision of a social safety net for those unable to adapt.

Keywords: climate change adaptation; farm decision changes; agriculture

\section{Introduction}

Farming and food production are the sectors of the Australian economy likely to be most directly affected by climate change [1-3]. Changes in temperatures, rainfall, and natural disasters directly affect the production of plant and animal products. Current individual farms' choices on the location of production, the mix of products to be produced, and the methods of production must be revised to increase food production for a larger population and to sustain farmers' incomes. Across most developed countries, including Australia, farmers have a historical track record of successful adaptation to variable climate events, changes in technology, changes in absolute and relative product prices, changes in the relative costs of different inputs, changes in general macroeconomics, regulation in the agricultural sector and other industry policies, and further circumstances [4-7]. This paper provides an overview of the support for the assertion the current institutional structure and its operation for farm decision-making, including adaptation to recent climate change and projected future climate change, will facilitate another round of successful farming adaptation via changes in the decisions made, in favor of different options.

Successful adaptation by farmers to climate change, so as to supply food and fiber and generate farmers' incomes, will involve complementary activities on the parts of farmers and the government. Operating in competitive markets, individual farmers have incentives to make and receive rewards for revised decisions in response to climate change. Importantly, each farmer has the advantage of information specific to each farm, which is necessary to assess the relative merits of different options. Each farmer has access to location-specific information about the interaction of effects of the climate, location, topography, soils, responses to different production methods, and so forth on the production, costs, and returns for different methods of farming.

Governments have several important complementary roles to play to support farmers to evaluate their options in response to climate change and then implement adaptive choices. Information on climate trends and weather forecasts have public good properties 
of non-rival consumption and high costs of exclusion. Information on both would be underprovided if left to a competitive market. Government intervention to increase the supply of research and development (R\&D) related to developing alternative production methods more suited to changed climate conditions, and to assist in evaluating the relative effects and benefits of different options, has become a new direction for ongoing government intervention in the provision of $\mathrm{R} \& \mathrm{D}$ for the agricultural sector. Good property rights established and monitored by the government facilitate the transfer of land, water, and other farm production inputs from lower-value uses and users to higher-value uses and users. Not all farms will successfully adapt to climate change. As has been the case over history in adapting to changes in other circumstances, a government social security safety net remains important for equity reasons. This paper uses Australia as the case in an illustrative study of farm adaptation to climate change.

Evaluation of the institutional arrangements for climate change adaptation adds to, and builds upon, studies by staff of the Australian Bureau of Agriculture and Resource Economics and Sciences (ABARES), who provide estimates using simulation models of the effects of climate change over recent decades on farm production and incomes by region in Australia [8,9]. They estimate that there will be reductions to come in terms of production and incomes. Large variations in the magnitudes of adverse effects are estimated across different regions, in part because of different forms of climate change and due to variation across regions in the current product mixes and production methods. Making quantitative estimates of the effects of climate change and of adaptation responses using simulation models and time-series econometric estimates is challenging. The challenges faced include: separating climate change effects from natural climate variability effects; separating adaptation to climate change from adaptation to new technology, changes in product and input prices, and other ongoing structural changes; and allowing for the high level of imperfect knowledge about current as well as future climate change, and changes in other circumstances. The focus of this paper on the institutional arrangements to facilitate climate change adaptation seeks to recognize the heterogeneity of different individual farms' circumstances, ongoing changes in several sets of circumstances affecting the relative merits of different choices, imperfect information, and the inflow of new information.

The rest of the paper is organized as follows. Section 2 provides details of the competitive structure of the farming sector and its operation. Section 3 summarizes the available information on the climate change observed to date and projections for the next two decades of changes that will face farms across Australia. Successful adaptation by the farming sector and farming families over history to changes in technology, product markets, and input costs is described in Section 4 . A repeat of history indicates the likely processes and results of farmers' adaption to climate change. Complementary supporting roles for governments, to assist farmers' adaptation to climate change, are discussed in Section 5. Then, the final section concludes the paper.

\section{The Farming Sector}

Farms are at the upper end of the food supply chain. In Australia, on average, farms spend about half of their gross profits on the purchase of machinery, casual labor, water, energy, fertilizers, and expert advice, to combine with land and owner labor and management $[10,11]$. Farms' plant and animal products are sold to others along the supply chain who add transport, storage, processing, and distribution services to their value by the time they reach final consumers. About 40 percent of aggregate Australian farm output is for domestic consumption, with the other 60 percent exported [11].

The farming sector as an aggregate and for individual commodities has a highly competitive market structure [10]. Family owned and operated farms are the dominant business operation. They account for about 95 percent of the 88,700 farm establishments in Australia [12]. For most products and locations, these farms are of sufficient size to capture the lower average cost benefits of economies of scale. At the same time, the 'owner and operator' farm gains from the low costs of coordination and management, drawing on farm- 
specific information about details of the farm production environment and processes. Only for a few products, including poultry and some horticulture, are there formal integrated links of farms and other firms down the supply chain. Individual farmers then are price takers in both the purchase of inputs and sale of outputs. In a Darwinian world of survival of the fittest, competitive pressures require individual farmers to regularly review their options to increase their output and reduce their costs, to maintain and increase their net returns as the market and production circumstances evolve over time.

A simplified model of farm decision-making is used as a framework to evaluate the effects of climate change on the choices available to farmers when it comes to what to produce and by what methods, along with the relative merits of different choices. This provides a framework for understanding the history of farm adaptation to changes in technology, product and input prices, and other circumstances, as discussed in Section 4. Farmers choose the products to produce, production methods, and inputs to purchase to maximize their profits. A key relationship and set of constraints facing each farmer is a production function that links outputs to inputs, with the climate being a key determinant. The prices of outputs and purchased inputs are set by wider market and economy forces. More formally, we choose Yij for product i (for example, wheat, beef, or apples) and for production factor $\mathrm{j}$ (for example, variety chosen, cultivation method, or fertilizer rate), using purchased inputs Xijk for product $\mathrm{i}$ and production method $\mathrm{j}$ (with $\mathrm{k}$ including, for example, chemicals, machinery, or hired labor), to maximize

$$
\text { profit }=\sum \sum\left[\text { Pi Yij }-\sum C k \text { Xijk }\right]
$$

subject to

$$
Y_{i j}=f\left(C l i m a t e, \text { Landi, } X_{i j 1}, X_{i j 2}, \ldots,\right. \text { Xijn, Technology) }
$$

and market prices $\mathrm{Pi}$ for the outputs and $\mathrm{Ck}$ for the purchased inputs.

The climate, as a set of exogenous circumstances, refers to multiple attributes, including temperature, rainfall, wind, and adverse events. Individual farmers hold information about these attributes and their effects on production. Landi refers to land allocated to the production of product $i$, and it has multiple attributes, including soil type and depth, slope and aspect, and individual farmers' information about the productivity of their land. Xijk refers to purchased inputs $\mathrm{k}$ to produce product i via production method $\mathrm{j}$. Purchased inputs include labor, machinery, energy products, fertilizer, and purchased expertise. Technology embraces several factors including the available plant and animal genetic material, machinery, and management expertise.

While not all farmers seek to maximize the profits of (1), with some treating farming as a preferred lifestyle, a competitive Darwinian survival of the fittest world is a strong driving force. Over time, most farm families compare their returns from farming with the returns of alternative income options in other parts of the economy, and they have the option of selling and reallocating their funds and labor from farming for use in other sectors of the economy.

The above model provides an important background to understanding farmers' adjustment to climate change. First, the climate is an important determinant in the production function (2). The output response to farm production depends on the direct properties of the local climate in its many dimensions, including the amount/level and seasonal pattern of rainfall and temperature. In addition, climate outcomes have secondary effects on other inputs, including the prevalence and effects of pests and diseases, and for irrigators, on the availability and price of water.

Second, individual farmers hold private information about detailed attributes of their property as it affects the production function (2). This information includes soil types and capacities, responses to different production practices, and climate factors, along with the effects of these variables on the growth and output of plants and animals, indirect climate effects on pests and diseases, and the responses of crop and animal production to different production methods. Available information about these and other attributes of 
the production function specific to the individual farm are forever evolving in response to new technology, new available machinery, and changing output and input market prices.

Third, and as will be discussed in more detail in Section 4, over history, Australian farms have successfully adjusted their decision-making in response to changes to technology, the market prices of outputs and inputs, and due to variation of climate or seasonal conditions. Adaptation to climate change is another version or round of farmers' adjustments in response to a history of many changes in their opportunities and circumstances.

\section{Climate Change Facing Australian Farmers}

Information collated by the IPCC [1], and more specific details for Australia by the CSIRO and BoM [2] and by the Australian Academy of Science [3], describe significant and varying patterns of climate change for farmers in different regions of Australia over recent decades, and further changes are predicted for the next three decades. Key changes have been seen for temperature, rainfall, and in some regions, natural disasters, as well as higher sea levels in coastal areas. Climate change directly affects the production function (2) above that is available to most farms, namely, the Climate variable. In turn, farmers' decisions to make changes in response to changes in the available production function (2) result in changes to the outputs, returns, and farm incomes. Key climate changes in recent years and the projected changes over the next two decades, as well as some of the implications for necessary farming changes in different regions of Australia, as discussed by the Australian reports [2,3], are summarized in this section.

Current and projected higher temperatures, and changes in the variability of temperatures, are universal, but often with different magnitudes region to region. For example, the CSIRO and BoM [2] report an average temperature increase for Australia for the 2001 to 2020 period of $1.4^{\circ} \mathrm{C}$ when compared with the 1950 to 1999 period. While subject to some uncertainty about the magnitudes, further increases are projected through to 2050.

Higher and more variable temperatures cause changes in the farm production functions (2), and then changes in outputs, costs, and returns. Production function changes include changes to the growth rates of different plant and animal species, output responses to different plant and animal production methods, changes to the best times for planting and harvesting, effects on comfort and productivity of farm animals, and in many northern regions of Australia, decreased suitability of the working conditions for farm labor.

Rainfall patterns have changed with climate change over recent decades, and they are projected to change further in the future but taking different courses across the continent. In both the southwest and southeast farming regions, the average rainfall is falling and becoming more variable. Further, to date, the rainfall reductions and variability have been larger during the important cooler months when most plant growth takes place. In contrast, rainfall is expected to increase in much of northern Australia, and especially the northwest. The CSIRO and BoM [2] report for the last 20 years, relative to the 1950 to 1999 period, a fall in the average annual winter rainfall (for April to October) of 20 percent in southwest Australia, 12 percent for southeast Australia, and an increase of 3 percent for northwest Australia. More extreme heavy rainfall events are expected in some regions.

A combination of lower rainfall and higher temperatures reduces inflows to rivers and dams, providing less water for irrigation (and other uses) in southern Australia [13] and potentially reduced recharge rates for underground water.

Observed changes in recent decades in temperatures and rainfall are estimated to have reduced farming production and farm incomes across southern Australia. Hughes et al. [9] estimate an average reduction in net farm returns for the average farm due to climate changes (also estimated by the CSIRO and BoM [2], as noted above) in recent decades, relative to the last half of the twentieth century, of around 23 percent, assuming no other changes to the production function (2) or to product and input costs (3). The estimated reduction of returns has varied by farm product (i.e., with cropping adversely affected more than livestock), region, and farm type, with smaller farms losing more than large farms. The variability of returns has also increased. 
Drawing on the CSIRO and BoM [2] climate change projections through to 2050, Hughes et al. [9] project further reductions in farm production and incomes in the absence of adaptation, but with considerable uncertainty about the magnitudes of effects.

Climate change-driven increases in ocean levels with associated coastal flooding and salination will directly put some farming areas out of production. Yet, the importance of the affected farms relative to national farming production is anticipated to be small.

In many farming regions, the risks of natural disasters are projected to increase [2] For most of southern Australia, a combination of higher temperatures and less rainfall will bring more frequent and longer drought periods, and higher risks of bush fires. Further, the severity of cyclones in northeastern Australia is projected to increase, though perhaps not the frequency [2]. While most farmers have experienced and adjusted to natural disasters over history, the likely greater frequency of, and severity of, natural disasters will alter both the options available to farmers and the relative merits of the different options.

Climate change alters the options available to farmers and their relative merits in much the same way as has occurred over history with changes in technology, output and input prices, and other circumstances. For climate change, as for changes in circumstances that have occurred, there is imperfect knowledge about the details, including the relative merits of alternative choices for what products to produce and by what production methods. In this context of imperfect information, adaptation involves experimentation and then repeated revision of decisions as additional information becomes available. Of course, not all changes in response to climate change will be successful or profitable.

\section{A History of Successful Adaptation to Changes}

Since the arrival of the English in 1788, Australian farmers have faced marked changes in their circumstances and in the available options for which products to produce and by which production methods. In the context of the farming decision models of (1), (2), and (3), every decade has seen great changes in the product prices, $\mathrm{Pi}$, input costs, $\mathrm{Ck}$, and details of the production function (2). Marked advances in technology have been a key driver of changes in the production function via the technology term in (2). Examples of new technology include new genetic material for plants and animals, changes to the available types and productivities of machinery and equipment, access to fertilizers, means of pest and disease control, and management strategies. Some decades have also been marked by changes in government regulation and commodity policies.

Given the evolution of changes in the farm decision environment over history, the majority of farmers have responded by changing their production and market circumstances in order to increase or protect their returns by changing their choice of products to produce and the production methods. Australian economic history studies, including those by Maddock and McLean [4], Williams [5], McLean [6], Edwards and Bates [7], and many others, provide detailed reviews of changes over history in farm decision-making circumstances, of farms' changes in response to the changes in circumstances, and of the effects of farms' changes on their outputs, input purchases, incomes, and other economic factors. This section provides a selective summary of the more detailed and better documented studies to highlight some of the major decision-related contextual changes, to illustrate successful adaptation by Australian farmers over history to a changing world of opportunities and constraints.

Technological change and increased productivity have taken many forms. Examples include: new genetic material options for plants and animals, fertilizers and their more targeted application, better control of diseases and pests, improved management methods, different tillage and irrigation systems, and more advanced machinery and equipment. The productivity gains have resulted in additional output for given inputs. In many regions new technology has extended the profitable production of many products.

A key trend of structural change for farms over the past hundred years has been driven by a combination of technical advances in available machinery and equipment and by rising real labor costs across the general economy. Together, these factors have led to 
changes to substitute capital for labor and to amalgamate many farms into larger farm sizes. Most of these capital-for-labor input mix substitutions have also increased farm productivity and the share of purchased inputs in farm production, and brough about a shift toward hiring specialist and casual labor to complement owner labor.

Relative product prices have fluctuated over history, leading many farmers to change their product output mix to maintain and increase their returns. The causes of changes in the absolute and relative product prices of farm outputs have included a combination of: world market price fluctuations, changes in the Australian real exchange rate, lower transport costs, and changes in government agricultural product marketing policies. There is no reason not to expect further changes of prices in the future, and as in the past, with imperfect knowledge of both the directions and the magnitudes of changes.

Important from the perspective of farmers' skills to adapt to climate change is that over time, farmers have developed more successful decision-making strategies to adjust to the wide fluctuations in seasonal conditions that characterize most areas of Australian agriculture. Important climate fluctuations driving the production function (2) include variations in the timing and magnitude of rainfall patterns each growing period, periods of extreme drought, the available water for irrigation, and flood and cyclone events. The timing and magnitude of natural variations in the climate's seasonal conditions have been subject to imperfect information. Drawing on extensive meteorological data collected and analyzed by government agencies, and based on on-farm experiences and observation, farmers adjust their longer-term choices of products, stocking rates, fodder storage, tillage methods, and so forth for the purpose of income smoothing. Kingwell and Xayavong [14] draw on survey data to describe changes in the mix of enterprises, increased choice of lower-cost methods, and for many, increases in the farm size for broadacre farms in Western Australia in response to drought conditions. Hughes et al. [8] use simulation models to estimate different magnitudes of adverse drought effects on the averages and variability of farm incomes across different farm types and regions. Goesch et al. [15] discuss the operation of water markets in response to droughts, and in particular, highlight higher prices and reallocation of scarce and higher-priced water from annual crops, including rice and cotton, to perennial crops, including citrus, grapes, and almonds. Adamson et al. [16] explain the use of adaptive decision models by farmers to change their decisions in a context of imperfect information about the climate and in response to an inflow of additional information.

In addition, as part of the strategy for adaptation to the variability of farm decisionmaking circumstances, some farmers have diversified their sources of income with inclusion of off-farm employment and capital income to cover variations of seasonal conditions and the likelihood of natural disasters. For shorter-term decisions, farmers use forecasts of the climate to adjust their times of planting and harvesting, irrigation, destocking, and other when making decisions to improve their returns. Adaptation to climate change, when interpreted as a trend, adds another dimension to past and current decision-making choices in a world of variable climate conditions.

In recent times, farmers have had to adapt their decisions to incorporate wider community concerns about food safety and quality, environment amenity, and animal welfare.

Over history, most farmers, but not all, have adjusted their decisions on the mix of products to produce and locations to use, and have changed their production methods, in response to changes in technology, output prices, input costs, and other circumstances [4-7]. Farm productivity has trended upwards, and for many decades, rose at a faster rate than productivity growth in other sectors of the general economy. Aggregate farming output has trended upwards. Individual farms have expanded in size by most measures, and they have become more capital intensive and less labor intensive. The smaller number of larger farms have generated incomes roughly comparable to those obtained in other sectors of the economy. Yet, some farmers have moved to other sectors of the economy. As is the case for some operators in other sectors of the economy, not all farms have successfully adjusted to the changing circumstances, and some receive very low incomes. 
The current competitive industry structure, as over history and as it will in the future, provides the incentives and rewards for individual farms to adapt to changes in their circumstances, of which climate change is just one of the many ongoing changes that alter the relative returns of alternative choices on where to produce, what to produce, and the production method. This competitive industry structure recognizes: information and incentives for individual farms; uncertainty about the details of changes in the climate, technology, output and input costs, and other circumstances, leading to ongoing experimentation and re-evaluation of decisions as new information becomes available; and the heterogeneity of appropriate adaptation responses, including those to climate change, across different areas, farms, and over time.

\section{Government in the Game}

Government intervention is important to support and facilitate effective adaptation to climate change by Australian farmers. Complementary government roles include: supply of information about the climate; policies to support investment in R\&D to both develop and assess the relative merits of alternative choices; provision of property rights for farm inputs and outputs to support market transfers of farm production inputs from less productive to more productive uses and users; provision of transport, irrigation, and other infrastructure; direct contributions to better plan for, respond to, and recover from natural disasters; and provision of a safety net for those who fail to successfully adapt to climate change.

To a large extent, the important roles of the government in assisting farmers to adjust to climate change are an extension and evolution of policy interventions already in place. These policies have contributed to the adjustment of farmers to historical and future changes in technology, relative output and input prices, natural disasters, and other circumstances discussed in the previous section. Maddock and Mclean [4], Williams [5], and McLean [6] discuss the evolution and operation of government policies to support the effective operation of the private sector economy in general, and with some illustrative examples in agriculture, over history. Hughes et al. [9] point to largely the same government policy interventions as discussed below for assisting the agricultural sector to adapt to climate change.

Effective individual farms' responses to climate change require the farmers to have information about the different dimensions of climate change that affect them at the individual farm level of the production function (2) for different products, and for each product, for the different production methods. Included in the climate information needs are longer-term trends associated with climate change, and forecasts of climate variability over shorter periods. Detailed information at a regional level is of more relevance to the specific production circumstances of each farm than country- or state-wide information.

Meteorological information has the good public properties of non-rival consumption, and in most cases, also high costs of exclusion. Further, the benefits of meteorological information extend across the economy and to most households, not just farmers. If left to the market, the supply of information on climate change and weather forecasts would be grossly under-provided. As a result, the Australian government has directly funded the Bureau of Meteorology (BoM) to collect and analyze many dimensions of the climate, and to make the information and forecasts available for free to all businesses and households. With the impact of climate change now felt, government funds have been provided to other government departments and agencies to support the BoM in its research into climate change. Government funds are also required to support the distribution of climate change and weather forecast information for use by the general public, including farmers.

Technological changes in the form of different genetic strains for plants and animals, different production processes, more productive machinery, digital technology, and so forth, which are better suited to climate change, will be fundamental to the adaptation to climate change for most farmers. Government support for investment to assess the relative merits of new technologies and to evaluate the pros and cons of different options 
for the mix of products to produce and production methods, in a world of climate change, should be a component of the R\&D portfolio. As was the case for R\&D-driven technology change and productivity improvements for Australian farms in the history of the last one hundred years, as discussed in the preceding section, R\&D promoted by government policy interventions will be a basic contributor to successful climate change adaptation. The external benefits of R\&D are great, and they are especially important for the farming of thousands of family owned and operated businesses involved in the production of different products in different regions [17].

Current general forms of government provision of $R \& D$ and support for private investment in $R \& D$, to support better decision-making for farms in response to climate change, as well as for other continuing areas of productivity improvement, can internalize the external benefits of $R \& D$ and support climate change adaptation. These policy interventions include: direct government funding and delivery of R\&D; subsidies for private-funded R\&D, including tax concessions and a system of rural industry research corporations funded by a compulsory levy on farm products sold and a matching government subsidy; and the legislation of property rights in the form of patents for machinery and plant variety rights [17]. Tasks for government and private-sector investors in R\&D to assist farmers to adapt to climate change involve adjusting their R\&D portfolio mixes with reference to the changing constraints and opportunities posed by projected climate change.

Adaptation to climate change for many farms will include changes in the mix of land, water, and other inputs, as well as changes in the product mixes $[8,14,18]$. The option to transfer inputs between users, and with low transaction costs, facilitates beneficial trades for both the buyer and the seller, and thus contributes to increased farm and national productivity. Australian law and established market institutions and procedures for the transfer of land, water, machinery, labor, and other farm inputs between farmers and other industries can be considered appropriate.

The natural monopoly characteristic of the infrastructure providing transport, energy, communication, and other services for farms and wider rural communities means there is a need for direct government funding and supply in most cases, or government-regulated provision of infrastructure by the private sector. A component of farm adaptation to climate change will involve changes in the needs of different locations for infrastructure services. Governments then have a role to play in adjusting the infrastructure supply and pricing as a component of a strategy to successfully adapt to climate change.

Climate change is expected to change the frequencies and magnitudes of natural disasters affecting some areas of Australian farming and the wider community. Active government involvement is justified to internalize the external benefits of preparation for and responses to natural disasters, both for reasons of equity and to capture the benefits of economies of scale and scope in providing information about pending natural disasters, responding to emergencies, and assisting in recovery.

It is inevitable that not all farms, and especially farming families, will successfully adapt to climate change. To meet society's goals for equity, the general available safety net for all Australians will continue to be important. These policies include the systems of minimum incomes, and government supply of, or subsidies for, basic services such as education and health for all. Programs to assist retraining and relocation should be made available to the farm families, and other members of society, adversely affected by climate change.

\section{Conclusions}

Climate change for many farms will reduce the net benefits of many current decision made on the products to produce and the production methods. Adaptation involves recognition of the changing circumstances and their effects on returns, including in relation to current decisions, exploration of alternative options, assessment of the relative benefits and costs of the current and alternative options, and then changes of what products to produce and their production methods, to ones better suited to the changed climate. 
During history, Australian farms have successfully adapted to a range of changing circumstances. These changes have included new technology and machinery, more expensive labor, changes in product markets and prices, and changes in government policies. Successful adaptation has included larger farm sizes, substitution of machinery and equipment for labor, greater use of purchased inputs, changes in the mixes and locations of products produced, and above all, significant increases in productivity. Future changes in these and other circumstances, altering the patterns of returns for different farming options, are inevitable. One aspect of the adaptive changes has been more robust and productive choices to accommodate marked variations in seasonal rainfall and other conditions, and in some areas, the risks of natural disasters. In many respects, adaptation to climate change is another changing circumstance that farmers have faced throughout history.

Successful adaptation of the farming sector and its production of food and fiber in response to climate change will involve a mix of government contributions and selfinterested individual farms' changes. Information about climate change, and about alternative farming decisions and their pros and cons-and in many cases, R\&D to develop new options - have sufficient public use to require direct government funding, and in some cases, subsidies. The competitive market structure of the farming sector provides incentives and rewards for individual farmers to revise their decisions when their circumstances change, including as a result of climate change. Individual farmers draw on publicly provided information as well as their specific and detailed information about their farm to finetune each of their choices in consideration of the different options' relative merits. These farmers' changes, made to adapt to climate change, are relevant to the national interest.

Inevitably, and as has been the case throughout history when responding to changes in technology, input costs, and product markets, not all farmers will successfully adapt to climate change. As a result, some will leave the sector and others will find themselves in poverty. A general or economy-wide government income safety net and skill retraining programs will be important components of the climate change adaptation process.

Funding: This research received no external funding.

Institutional Review Board Statement: Not applicable.

Informed Consent Statement: Not applicable.

Acknowledgments: I gratefully acknowledge the comments and suggestions of the anonymous reviewers whose comments improved the paper.

Conflicts of Interest: The author declares no conflict of interest.

\section{References}

1. International Panel on Climate Change (IPCC). Climate Change and Land: An IPCC Special Report on Climate Change, Desertification, Sustainable Land Use, Food Security, and Greenhouse Gas Clashes in Natural Ecosystems; IPPCC: Geneva, Switzerland, 2019.

2. CSIRO; BoM. State of the Climate 2020; Commonwealth of Australia: Canberra, Australia, 2021.

3. Australian Academy of Science. The Risks to Australia of a $3{ }^{\circ} \mathrm{C}$ Warmer World; Australian Academy of Science: Canberra, Australia, 2021.

4. Maddock, R.; McLean, I. (Eds.) The Australian Economy in the Long Run; Cambridge University Press: Cambridge, UK, 1987; ISBN 0-521-32674-5.

5. Williams, D. (Ed.) Agriculture in the Australian Economy; Sydney University Press and Oxford University Press: Sydney, Australia, 1980; ISBN 0-424-00157-8.

6. McLean, I. Why Australia Prospered: The Shifting Sources of Economic Growth; Princeton University Press: Princeton, UK; Oxford, UK, 2013; ISBN 978-0-691-1547-1.

7. Edwards, G.; Bates, W. Antipodean Agricultural and Resource Economics at 60: Agricultural Adjustment. Aust. J. Agric. Resour. Econ. 2016, 60, 573-589. [CrossRef]

8. Hughes, N.; Galeano, D.; Hatfield-Dodds, S. The Effects of Drought and Climate Variability on Australian Farms. In ABARES Insight Report Issue 3; Australian Government: Canberra, Australia, 2019; pp. 1-22.

9. Hughes, N.; Lu, M.; Soh, W.; Lawson, K. Simulating the Effects of Climate Change on the Profitability of Australian Farms. In ABARES Working Paper; Australian Government: Canberra, Australia, 2021.

10. Productivity Commission (PC). Trends in Australian Agriculture. In Productivity Commission Research Paper; Australian Government: Canberra, Australia, 2005. 
11. Australian Bureau of Agricultural and Resource Economics and Sciences (ABARES). Insights: Snapshot of Australian Agriculture; Australian Government: Canberra, Australia, 2021.

12. Australian Bureau of Statistics (ABS). Value of Agricultural Commodities Produced, Australia, 2019-20; Australian Government: Canberra, Australia, 2021.

13. Productivity Commission (PC). National Water Reform; Productivity Commission Draft Report; Australian Government: Melbourne, Australia, 2021.

14. Kingwell, R.; Xayavong, V. How Drought Affects the Financial Characteristics of Australian Farm Businesses. Aust. J. Agric. Resour. Econ. 2017, 61, 344-366. [CrossRef]

15. Adamson, D.; Lock, A.; Schwab, K. Adaptation Responses to Increasing Drought Frequency. Aust. J. Agric. Resour. Econ. 2017, 61, 385-403. [CrossRef]

16. Goesch, T.; Legg, D.; Donoghoe, M. Murray-Darling Basin Water Markets; ABARES Research Report 20.5; Australian Government: Canberra, Australia, 2020.

17. Productivity Commission (PC). Rural Research and Development Corporations; Productivity Commission Report; Australian Government: Canberra, Australia, 2011.

18. Ghahramani, A.; Kingwell, R.; Maraseni, T. Land Use Change in Australian Mixed Crop-Livestock Systems on a Transformative Climate Change Adaptation. Agric. Syst. 2020, 180, 102791. [CrossRef] 